\title{
Signals of need in a cooperatively breeding mammal with mobile offspring
}

\author{
MARTA B. MANSER*†, JOAH R. MADDEN $\ddagger$ HANSJOERG P. KUNC*, SINEAD ENGLISH $\ddagger \&$ TIM CLUTTON-BROCK $\ddagger$ \\ *Verhaltensbiologie, Zoologisches Institut, Universität Zürich \\ $\dagger$ Mammal Research Institute, University of Pretoria \\ $\ddagger$ Department of Zoology, University of Cambridge
}

(Received 8 January 2008; initial acceptance 14 March 2008;

final acceptance 29 July 2008; published online $\mathbf{\square} \mathbf{\square}$; MS. number: 08-00015R)

\begin{abstract}
In many bird species with biparental care for young in the nest, hungry chicks beg repeatedly and parents adjust their feeding rate to the call rate of young. Repetitive calling also occurs in fledglings and in some mammals where offspring follow provisioners. It is not yet clear whether, in mobile systems with dispersed young where adults cannot compare the vocal behaviour of all young simultaneously, the calls represent a signal of need. We investigated repetitive begging by cooperatively reared meerkat, Suricata suricatta, pups that foraged with the group. Pups produced two types of begging calls: repeat calls over long periods and high-pitched calls mainly confined to feeding events. Food-deprived pups stayed closer to feeders, and begged for longer and more intensely by calling at a higher rate. Hungry pups increased both the rate of repeat calls, which were given continually, and the number of high-pitched bouts, but adults increased their food allocation only in relation to the rate of repeat calls. Our study indicates that hunger may lead to several changes in vocal behaviour, only some of which may be used by adults to assess need.
\end{abstract}

(C) 2008 The Association for the Study of Animal Behaviour. Published by Elsevier Ltd. All rights reserved.

Keywords: begging; call rate; cooperative breeder; meerkat; mobile begging system; signal of need; Suricata suricatta

In many species, adults adjust their provisioning rate to the begging intensity of offspring, whereby increased begging elicits increased food allocation (Ottosson et al. 1997; Krebs 2001; Glassey \& Forbes 2002; Wright \& Leonard 2002). Begging intensity has been shown to vary with offspring need (Hofstetter \& Ritchison 1998; Sacchi et al. 2002), the presence and behaviour of littermates (Johnstone 2004) as competitors (Leonard \& Horn 1996) or cooperators (Bell 2007), the presence of brood parasites (Kilner et al. 1999) and the receiver to whom the signal is addressed (Bell 2008). The relative influence of these

Correspondence: M. Manser, Verhaltensbiologie, Zoologisches Institut, Universität Zürich, Winterthurerstrasse 190, 8057 Zürich, Switzerland (email: marta.manser@zool.uzh.ch;mkproj@mweb.co.za).J. Madden is now at the School of Psychology, University of Exeter, Exeter EX4 $4 Q G$, U.K. H. Kunc is now at the School of Biological Sciences, Medical Biology Centre, University of Belfast, Belfast BT9 7BL, U.K. S. English and T. Clutton-Brock are at the Department of Zoology, University of Cambridge, Downing Street, Cambridge CB2 3EJ, U.K. factors on begging behaviour may depend on the social system and how offspring are spatially distributed. To understand the underlying mechanisms in parent-offspring communication, we not only have to measure the effect of these factors on the begging behaviour of offspring (signaller), but we also need to identify the specific signals affected, and how variation in these signals influences the provisioning rate of adults (receivers).

A close linkage between the behaviour of begging offspring and provisioning adults is expected where offspring honestly signal need and adults benefit by responding to such honest signals with increased feeding (Kilner \& Johnstone 1997; Royle et al. 2002). Although offspring may be expected to demand as much food as possible (Trivers 1974; Godfray 1995; Mock \& Parker 1997), their begging carries costs, not only immediately in terms of increased energetic expenditure (e.g. Chappell \& Bachman 2002) or predation risk (Leech \& Leonard 1997), but also indirectly through reduced fitness of parents and siblings, both current and future (Trivers 1974; Lessells \& Parker 1999). Therefore, a stable signalling strategy is reached 
when the benefits obtained by an offspring increasing its begging display are matched by the costs that an exuberant display imposes (Godfray 1995). Continued exaggeration of begging is prohibited by such costs, and so honesty is imposed on the signal to which the adult attends.

Begging behaviour in systems where the young are mobile and dispersed during foraging with the group may differ from that in stationary systems. In spite of the brief interaction time between parents and offspring in a stationary feeding system, adults can compare the begging intensity of all offspring simultaneously, and decide how often and whom to feed accordingly. In contrast, in the dispersed feeding systems of some fledglings (Smith et al. 2005; Draganoiu et al. 2006) and some mammals (Manser \& Avey 2000; Bell 2007), dependent offspring follow adults closely while they search for food. Group members are spread out and only one or a few of the offspring follow the same adult (Manser \& Avey 2000; Gilchrist 2004). Adults are not able to monitor the begging behaviour of all the offspring simultaneously, although vocal cues might be perceived from individuals further away. As adults have information on begging intensities of only one or a few offspring in their immediate vicinity, they may simply feed the nearest offspring (Manser \& Avey 2000; Brotherton et al. 2001) rather than assessing relative signals of need among dispersed young. Consequently, feeding events are spatially unpredictable for the young and it may be more important for them to ensure a close spatial position to the best feeders, to influence the food allocation rate of that particular individual by honestly signalling their hunger.

In the cooperatively breeding meerkat, Suricata suricatta, pups accompany the group foraging from about 25 days and continuously produce begging calls to solicit food from adults (Manser \& Avey 2000). Pups are fed invertebrate and small vertebrate prey by both parents and helpers until nutritional independence at around 3 months old (Brotherton et al. 2001). Helpers typically include full or half sibs of both sexes and unrelated immigrant males (Clutton-Brock et al. 2001). Pups disperse around the group and follow foraging adults, with each pup following an individual adult closely for several minutes, but moving regularly between them (Hodge et al. 2007). Pups are typically several metres away from siblings. In 95\% of pup feeds, the pup closest to the adult with food receives the food item (Brotherton et al. 2001). Experimentally fed pups spend less time than control pups begging close to potential feeders (Brotherton et al. 2001). Pups produce a repertoire of different vocalizations in different begging contexts (cf. Manser \& Avey 2000; Kunc et al. 2007; Fig. 1). While the group is foraging, pups give continuous 'repeat calls' (Fig. 1) at the rate of 60-90 per min (Manser \& Avey 2000). However, when pups observe an adult finding or carrying food, they typically switch briefly to the louder 'high-pitched call' (Manser \& Avey 2000; Fig. 1). With increasing age, foraging pups beg less and dig more for food by themselves, producing digging calls (Manser \& Avey 2000; Kunc et al. 2007). Playback experiments revealed that adults base their feeding decisions on the call amplitude (Manser \& Avey 2000) and preferentially try to feed a loudspeaker playing high-pitched calls rather than repeat calls in the crucial moment of food allocation (Kunc et al. 2007). Thus variation in the production of repeat or high-pitched calls may be used as a signal of need.

In this study we investigated how begging in dispersed young with multiple feeders varies according to hunger, and how variation in specific signals affects the rate at which adults bring food to dependent young. We compared food-deprived and experimentally fed meerkat pups in relation to (1) their spatial location relative to the closest feeder, (2) their begging rate and their use of specific call types, and (3) differences in the acoustic structure of their calls. We then tested (4) whether adults discriminated between the vocalizations of hungry and fed pups, and (5) how adults responded to increased rates of the different types of begging calls. Thus, we asked whether begging vocalizations of offspring in a dispersed system with cooperative care serve as signals of need, and in particular which aspects of the vocal behaviour indicate the nutritional state of the young and are used by adults to assess their need.

\section{METHODS}

\section{Study Population}

Data were collected on a wild but habituated meerkat population at the Kuruman River Reserve, South Africa $\left(26^{\circ} 58^{\prime} \mathrm{S}, 21^{\circ} 49^{\prime} \mathrm{E}\right)$, between 2002 and 2007. Details on habitat, climate and study population are provided elsewhere (Clutton-Brock et al. 1998). All animals were individually marked and habituated to close observation (within $0.5 \mathrm{~m}$ ). Experiments were conducted during the peak provisioning period when pups were 40-60 days old (Brotherton et al. 2001).

\section{Effect of Hunger on Begging Behaviour}

We used three experiments to test how begging behaviour changed with hunger. In experiment 1 , we tested whether pups changed their call rate after having received a single large prey item. In experiment 2 , we investigated whether the same pup called at a lower rate after a period of natural foraging in the group than immediately after it had been deprived of food for $1 \mathrm{~h}$. In experiment 3 , we compared several aspects of begging behaviour between fed and hungry siblings treated in the same way, since parameters other than call rate also appear to correlate with feeding rate (Brotherton et al. 2001). We measured the following behaviours of the pups: distance to feeder, proportion of begging versus other behaviour by pups, use of the different begging call types, call rate and the acoustic structure of the repeat calls.

\section{Experiment 1: supplementary feeding and begging rate}

The vocalizations of 18 pups from eight groups were recorded before and after the pups ate a supplementary food item. The pup was allowed to forage naturally with its group for at least 15 min after the start of the day's foraging. Its vocalizations were then recorded with a Marantz 


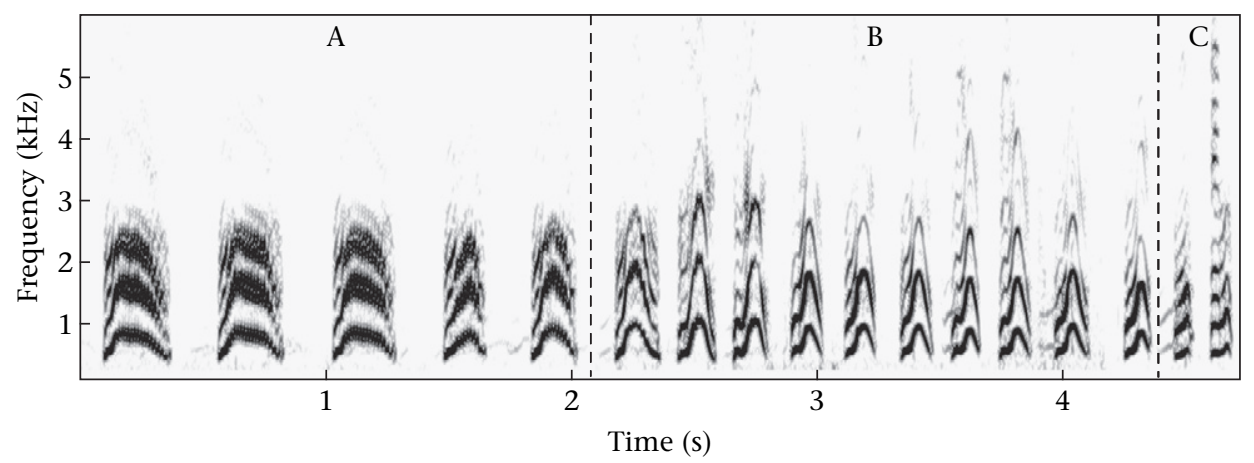

Figure 1. Real-time spectrogram of a pup giving repeat calls (A), switching to high-pitched calls (B), and then calling while eating (C).

PMD 670 recorder (sample frequency $44.1 \mathrm{kHz}$, resolution 16 bit) connected to a directional Sennheiser microphone (ME66 with K6 module) at a distance of $0.5-1 \mathrm{~m}$ for 5 min. We then placed a live scorpion (genus Opistophthalmus) weighing 1-3 $\mathrm{g}$ in the hole where a pup was digging. Vocalizations of the pup were recorded for another $5 \mathrm{~min}$ after it had eaten the scorpion. During the whole period, we ensured that the pup was not eating any other food item.

\section{Experiment 2: food deprivation and begging rate within individuals}

The begging vocalizations of 10 pups from four groups were recorded, first when the same pup was at a natural level of hunger, and then when it had been deprived of food for $1 \mathrm{~h}$. A focal pup was allowed to forage naturally with its group for at least $1 \mathrm{~h}$ after the start of the day's foraging. Its vocalizations were then recorded for $10 \mathrm{~min}$. The focal pup was removed from the group and kept in isolation in a box, at least $200 \mathrm{~m}$ away from the group for $1 \mathrm{~h}$, without any food. At least one other pup was left with the group to continue begging. After the return of the focal pup to the group and normal foraging had resumed, we recorded its vocalizations for $10 \mathrm{~min}$. From these recordings, we counted the repeat calls (Manser \& Avey 2000) given during $10 \mathrm{~s}$ periods, separated by $30 \mathrm{~s}$ intervals, and calculated the mean number of calls/10 s.

\section{Experiment 3: food deprivation, patterns of association and acoustic structure of begging calls}

We removed two female and two male pups from the same litter in seven groups and kept them in a box (as described above) for $1 \mathrm{~h}$. On the first day, we removed two pups of the same sex of which one did not receive any food, while the other was fed a scorpion (as described above) every $15 \mathrm{~min}$ and one immediately before they were released back to the group (equalling natural provisioning rates). After the two pups had been released and the group resumed foraging, we recorded the behaviour, vocalizations and distance to the closest adult of each pup, and how often it was fed, alternating three times for $10 \mathrm{~min}$ over $1 \mathrm{~h}$ between the two test subjects. Two days later, we carried out the same treatment with the other two pups in the same group. We alternated the order of removing first female or male pups in the different groups, and used pups most similar in weight if more than four pups were available per group. We also alternated the order of our focal observations, following first the fed pup and then the unfed pup after releasing them back to the group.

We followed the pup with a microphone, recording its vocalizations on one channel of the audio recorder, and the observer describing its behaviour into the second channel simultaneously. Pup behaviour was categorized as: (1) begging: pup following one or several adults, producing repeat calls; (2) digging: pup digging for food by itself, producing digging calls; (3) excited: pup producing high-pitched calls and approaching feeder; (4) eating: eating or handling a prey item such as a millipede or scorpion; (5) resting: pup lying down and not begging, or pups play fighting. We analysed the distance pups spent in relation to feeders $(<1 \mathrm{~m}, 1-2 \mathrm{~m}, 2-5 \mathrm{~m},>5 \mathrm{~m})$ during the first $10 \mathrm{~min}$ period after releasing the pups (but only from a subset of pups). For the activity pattern, we included all three 10 min periods of recording for each pup (to increase the likelihood of the occurrence of feeding events and associated behaviour) and summed the total period spent in each behaviour described above. We then calculated the proportion of time a pup spent begging versus the other categories of behaviour over the period when the group was foraging without interruption by predator encounters. As high-pitched calls were given less often, we calculated the frequency with which they were given rather than their duration.

We calculated the rate of the two call types given in the context of begging. For each pup, the repeat call rate was calculated by measuring the time taken to give 10 of these calls (with 10 intervals), at the beginning of every minute over $20 \mathrm{~min}$. Of these 10 calls, the duration (ms) of the first three calls and the subsequent intervals were measured as well. Since a $20 \mathrm{~min}$ period often did not include a bout of 10 high pitched calls, we analysed the duration of three calls and the subsequent interval in the middle of the bouts. We extracted the calls from the sound files and measured call and interval duration using CoolEdit 2000 v.1.1 (Syntrillium Software Corporation, Phoenix, AZ, U.S.A.) from spectrograms with FFT length 1024, frequency resolution $10 \mathrm{~Hz}$ and time resolution $2.9 \mathrm{~ms}$.

To quantify the acoustic structure of the repeat calls, we measured temporal parameters (call duration; time of the peak of the fundamental frequency as a measure of the 
speed in reaching the highest point in the global modulation) and frequency parameters (fundamental frequency at start, end and the peak describing global modulation) previously discussed in the literature to express offspring need (Weary \& Fraser 1995; Sacchi et al. 2002). We extracted from the first two 10 min periods for each pup every $2 \mathrm{~min}$ a repeat call of high signal to noise ratio (resulting in a total of 10 calls per pup). For each call, we measured the fundamental frequency at the start and end $(\mathrm{Hz})$ and the peak of the fundamental frequency $(\mathrm{Hz})$ using the power spectrum analyses in CoolEdit 2000. We placed the cursor in the spectrogram for the measurement of the start frequency at $5 \mathrm{~ms}$ after the start, and for the end frequency at $5 \mathrm{~ms}$ before the end of the call, and made the respective measurements from the power spectra. To avoid inconsistent measurements caused by local modulation within a call, we placed the cursor in the centre of a down or up modulation in the fundamental frequency. The duration (ms) of these calls and the time of the peak of the fundamental frequency (ms) were measured from the spectrogram (see above). In addition, we measured the entropy of the calls with Avisoft-SASLab Pro 4.38 software (Avisoft Bioacoustics, Berlin, Germany). Calls were sampled at $11.025 \mathrm{kHz}$ with FFT length 1024, frequency resolution $10 \mathrm{~Hz}$ and time resolution $2.9 \mathrm{~ms}$.

\section{Effect of Begging Calls on Adult Behaviour}

We compared the amount of food that adults tried to provision to a pair of loudspeakers depending on whether the calls of fed or hungry pups were played. In seven groups, the speakers were simultaneously broadcasting recordings of the same pup: from one speaker when it was hungry and from the other speaker when it was fed, collected from pups in the food deprivation experiment 2 . Playback stimuli of pup begging calls were edited in CoolEdit 2000 to match amplitude and remove excessive background noise (e.g. loud bird calls) in the original recordings. Each recording lasted for $10 \mathrm{~min}$ and was repeated six times to provide a $1 \mathrm{~h}$ experiment. Edited sound files were played back at the natural amplitude (Manser \& Avey 2000) of begging pups taken at other groups using a SanDisk Sansa and Creative Zen digital player broadcast through Sony walkman speakers (SRS A60). Each loudspeaker was carried by a person who followed subordinate helpers, matched for age and sex, at a distance of $4-5 \mathrm{~m}$ in a constant orientation. This allowed us to simulate a begging pup in the group, with no experimenter bias as to where speakers were positioned. A feed to a speaker was defined as when an adult approached within $1 \mathrm{~m}$ of the speaker carrying a food item and no pup was within $1 \mathrm{~m}$ of the speaker.

Food-deprived and fed pups differed markedly in two aspects of their calling behaviour: the rate of repeat calls and the number of high-pitched bouts given. Therefore, we conducted additional playback experiments to test independently the effect of variation in each call type on adult provisioning rate. We tested how adults responded to increases in begging rates by playing back $30 \mathrm{~min}$ of low-rate and $30 \mathrm{~min}$ of high-rate repeat calls, presented in a random order, in each of nine groups. The playback was made using the equipment described above, with the speaker positioned $2-4 \mathrm{~m}$ from the dominant female; thus it constantly moved around the group. Playback cuts were made from recordings of female pups from a different group, by either adding or removing periods of background noise between calls to create the low (40 calls/ min) and high (120 calls/min) treatments, respectively (values within the natural range). A new cut was used for each test. The playback experiment was preceded by a $20 \mathrm{~min}$ habituation period of calls at an intermediate begging rate. We then tested the effect of increased numbers of high-pitched bouts on provisioning rate in seven groups, using the two-loudspeaker design as described above. We played calls of the same pup with a constant repeat call rate (60 calls/min), but variable numbers of highpitched bouts: either few (8/1 h playback) or many (28/1 h playback).

\section{Statistics}

Statistical analyses were conducted in R (R Development Core Team 2005). We analysed feeding experiments 1 and 2 and the playback experiments using Wilcoxon signedranks tests, owing to small sample sizes and the data not being normally distributed. For the feeding experiment 3 , we used the lme function in 'MASS' with the restricted maximum likelihood method and type III sums of squares. We ran the analysis on both the raw and the arcsine-transformed data. Graphical inspection of the residuals did not show differences in homogeneity and normal distribution. Furthermore, the $F$ values as well as the $P$ values were similar. Thus, we report the test statistics according to the data presented in the figures. We analysed the proportion of time close to a potential feeder as a function of hunger level (fed or deprived) and distance to feeder. We analysed the number of feeds as a function of hunger level and included time begging, number of repeat calls or the number of high-pitched bouts. We analysed the change in acoustic parameters as a function of hunger level. In all models group identity and sex were always included as random factors in each model and dropped if redundant (when the variance component was less than $10^{-5}$ ). Interactions were dropped if the $P$ values for the interaction were above 0.1 (Venables \& Ripley 2002; Engquist 2005). All statistical tests used were two tailed.

\section{Ethical Note}

We were concerned about possible rejection of removed and reintroduced pups by remaining group members. However, removing the pups from the group to control their hunger level was the least stressful approach, as disruption was kept to short periods when we removed and released them. Other options, such as preventing feeds while foraging by keeping adults physically away from the pups would have had a repeated impact over the whole hour. Depriving pups of food for $1 \mathrm{~h}$ is a slightly 
extreme natural situation. However, while pups typically get fed every 10-20 min (Brotherton et al. 2001), they sometimes have to wait up to an hour, particularly in small groups with more pups than adults (unpublished data). We never observed any short-term or long-term adverse effects on the behaviour of either fed or deprived pups or the other group members when carrying out these removals. We made maximum use of the paired-sample design to minimize sample size and we removed the minimum number of pups necessary to test the hypotheses posed.

Removal was achieved by picking up the pup and placing it in a fabric bag before transferring it to a large $(75 \times 50 \mathrm{~cm}$ and $50 \mathrm{~cm}$ high), opaque, lidded but ventilated plastic box that contained a layer of sand that had been prewarmed by a hot water bottle or sunlight. The box was carried away to a location at least $200 \mathrm{~m}$ from the foraging group. The pups showed some signs of stress by calling when initially put into the box, but as they were out of audible range of the group they calmed down within $5 \mathrm{~min}$. The other group members did not respond to the pups being taken away, as there were always begging pups left in the group. Pups were continually monitored for the hour during which they were removed. We reintroduced them in the centre of the group, opening the box facing foraging adults but out of sight of the dominant female and away from other pups. The other group members inspected the released pups by sniffing and marking them and then resumed foraging after 1-2 min. Both fed and deprived pups resumed normal foraging behaviour immediately after this inspection.

Playback experiments were conducted in a way not to confuse the group or habituate them to the loudspeaker. Whenever the loudspeaker was approached by any of the potential feeders, the volume of the calls was reduced and finally ceased to imitate the disappearance of a pup and lead the attention of the individual away from the speaker to a real pup.

The study was carried out under licences issued by the Northern Cafe Conservation Service and the ethical committee of Pretoria University, South Africa.

\section{RESULTS}

\section{Effect of Hunger on Begging Behaviour}

Begging behaviour in pups was influenced by their hunger, specifically the rate of the most frequently given repeat calls. Pups begged at a lower rate immediately after having been fed a large food item than during their usual time spent foraging with the group (Wilcoxon signed-ranks test: $Z=2.33, N=18, P=0.02$; Fig. 2 ). The same pups begged at a higher rate when they had been deprived of food, than when they had been naturally foraging with the group $(Z=2.23, \quad N=15, \quad P=0.026$; Fig. 2). Food-deprived pups also spent more time within $1 \mathrm{~m}$ of potential feeders than their fed siblings (generalized linear mixed models, GLMM: $F_{1,10}=23.71$, $P<0.001$; Fig. 3a) and spent more time begging intensely $\left(F_{1,19}=36.52, P<0.001\right.$; Fig. 3b). Food-deprived

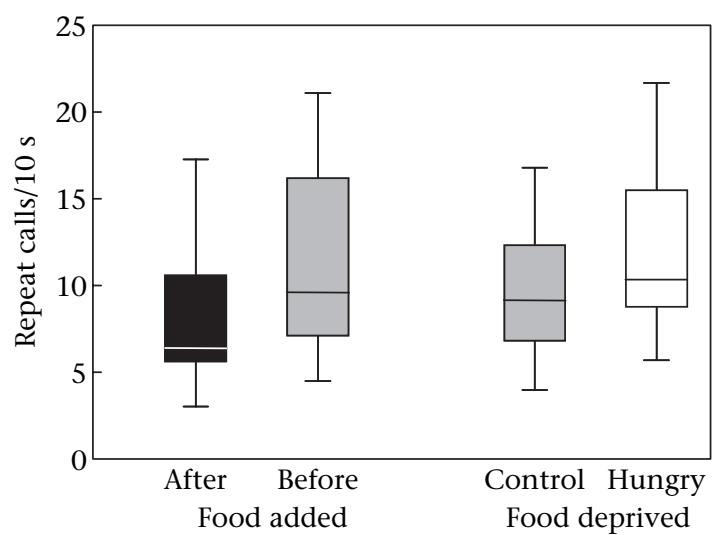

Figure 2. The effect of food supplementation and food deprivation on begging rates (median with interquartile range) of meerkat pups. Repeat call rates of pups are shown after and before the pups had been fed with a scorpion (food added, $N=18$ ) and under control conditions and after they had been deprived of food for $1 \mathrm{~h}$ (food deprived, $N=15$ ).

pups gave repeat calls at a higher rate than their fed siblings $\left(F_{1,19}=10.25, P=0.005\right.$; Fig. $\left.3 \mathrm{c}\right)$ and gave more bouts of high-pitched calls $\left(F_{1,19}=25.60, \quad P<0.001\right.$; Fig. 3d), although the rate of calls within these highpitched bouts did not change $\left(F_{1,19}=0.39, P=0.54\right)$. Of all the acoustic parameters we measured, only temporal aspects differed between deprived pups and their fed siblings, whereby duration and time of the peak frequency correlated with each other (Table 1).

\section{Effect of Begging Behaviour on Adult Feeding Rate}

Adults discriminated hungry from fed pups by provisioning hungry pups at a higher rate. Pups that were food deprived for $1 \mathrm{~h}$ and then returned to the group received a higher proportion of feeds from adults than when not food deprived (median $=0.30$, interquartile range, IQR $0.26-0.36)$ and competing with food-deprived siblings (median $=0.48$, IQR 0.38-0.56; Wilcoxon signed-ranks test: $Z=2.354, N=15, P=0.019)$. In the same way, fooddeprived pups received more prey items $(\bar{X} \pm \mathrm{SE}=6.5 \pm$ $0.6)$ than their fed siblings $(\bar{X} \pm \mathrm{SE}=4.0 \pm 0.4$; GLMM: $\left.F_{1,19}=11.15, P=0.004\right)$. The number of feeds pups received was influenced by the time they spent begging $\left(F_{1,18}=5.3, P=0.034\right)$ and tended to be influenced by hunger level $\left(F_{1,18}=3.54, P=0.08\right.$; Fig. $\left.3 \mathrm{~b}\right)$. The number of feeds pups received was also related to their rate of repeat calls $\left(F_{1,17}=5.08, P=0.04\right)$ and hunger level $\left(F_{1,17}=5.08\right.$, $P=0.04$; interaction: call rate*hunger level: $F_{1,17}=4.63$, $P=0.046$; Fig. 3c). Furthermore, feeding rate was influenced by the number of bouts of high-pitched calls $\left(F_{1,17}=16.07, P=0.01\right)$ but not hunger level, although the significant interaction confirmed that food-deprived pups gave more high-pitched bouts than fed pups $\left(F_{1,17}=0.7, P=0.4\right.$; interaction: number of bouts*hunger: $F_{1,17}=8.36, P=0.009$; Fig. 3d).

The specific aspect of a pup's calling behaviour that strongly affected adult feeding behaviour was its rate of repeat calls. Adults preferentially fed speakers playing back 

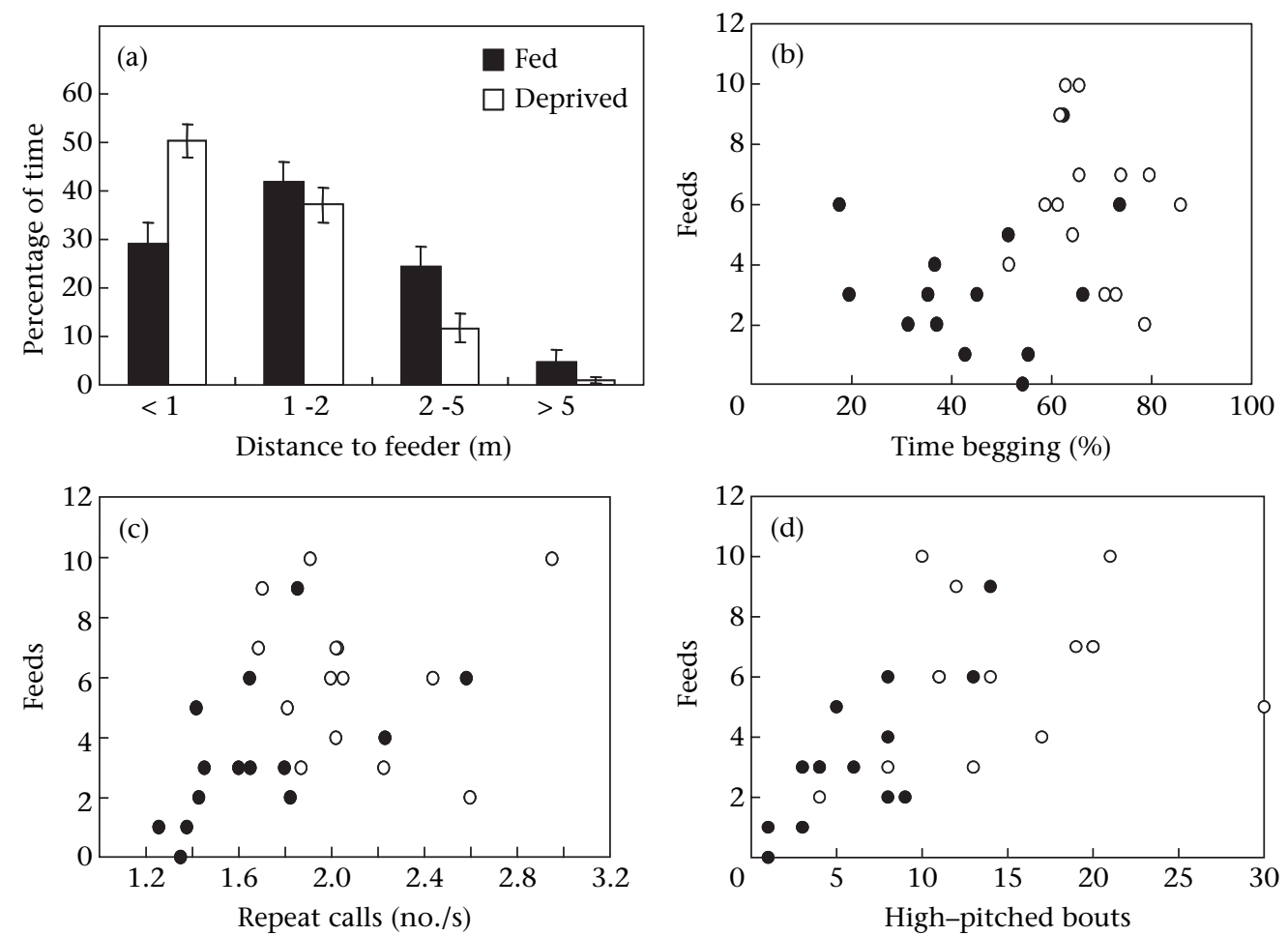

Figure 3. (a) Time $(N=10, \bar{X} \pm 1 \mathrm{SE})$ spent by fed and food-deprived pups following potential feeders within different distance categories after being held in a box for $1 \mathrm{~h}$. (b-d) Number of feeds by adults to fed $(0)$ and food-deprived pups $(O)$ in relation to (b) the percentage of time spent begging and hunger level, (c) the rate of repeat calls and hunger level and (d) the number of high-pitched calls given and hunger level.

the recording of a pup when it was hungry, as opposed to the recording of the same pup when it was fed (Wilcoxon signed-ranks test: $Z=2.02, N=7, P=0.043$; Fig. 4a). When we broadcast the playback of begging calls at a high rate, adults fed more food items than when exposed to the playback of the same begging calls at a low rate $(Z=2.37, N=9, P=0.018$; Fig. $4 \mathrm{~b})$. Adults did not respond to variation in the number of high-pitched bouts ( $Z=0.95, N=7, P=0.34$; Fig. 4c).

\section{DISCUSSION}

Hunger altered several aspects of pup begging behaviour in meerkats. Food-deprived pups followed adults more closely and spent more time begging. The rate at which pups gave repeat and high-pitched calls varied with their level of hunger. However, whether adults provisioned pups at a higher rate depended on an increase in the rate of repeat calls and not on the frequency of high-pitched bouts. Therefore, the constantly given repeat calls appeared to function as signals of need, while the high-pitched calls, which were confined to feeding events, influenced the decision on food allocation more immediately.

In meerkats, the pup closest to the adult with food gets the highest proportion of feeds (Brotherton et al. 2001). Proximity to the feeder is also important in other species with mobile young (Smith 2005) and for nestlings in stationary systems (Leonard et al. 1988; McRae et al. 1993; Kölliker et al. 1998). The close distance of a pup to the feeder may be crucial for several reasons. The closest pup is most likely to be perceived as the loudest and may

Table 1. Acoustic parameters of repeat calls given by fed and food-deprived pups during the hunger experiment

\begin{tabular}{lcccc}
\hline Acoustic parameters & Fed & Food-deprived & $F_{1,16}$ \\
\hline Call duration (ms) & $357.9 \pm 18.8$ & $282.9 \pm 14.1$ & 20.64 \\
Call entropy & $0.55 \pm 0.007$ & $0.54 \pm 0.007$ & 0.18 & $<0.001$ \\
FF start (Hz) & $465 \pm 9.4$ & $466 \pm 12.3$ & 0.63 & 0.68 \\
FF end (Hz) & $473 \pm 13.9$ & $462 \pm 9.7$ & 1.72 & 0.04 \\
FF peak (Hz) & $684 \pm 19.5$ & $702 \pm 19.1$ & 0.34 \\
FF delta (Hz) & $219 \pm 17.7$ & $237 \pm 22.0$ & 0.34 \\
FF peak time (ms) & $134 \pm 15.9$ & $96 \pm 6.7$ & 6.62 & 0.85 \\
\end{tabular}

Means are given $\pm 1 \mathrm{SE}$. FF = fundamental frequency; start = at beginning of call; end = at end of call; peak = highest frequency of FF within call; delta = peak - start; peak time = time of peak frequency. 

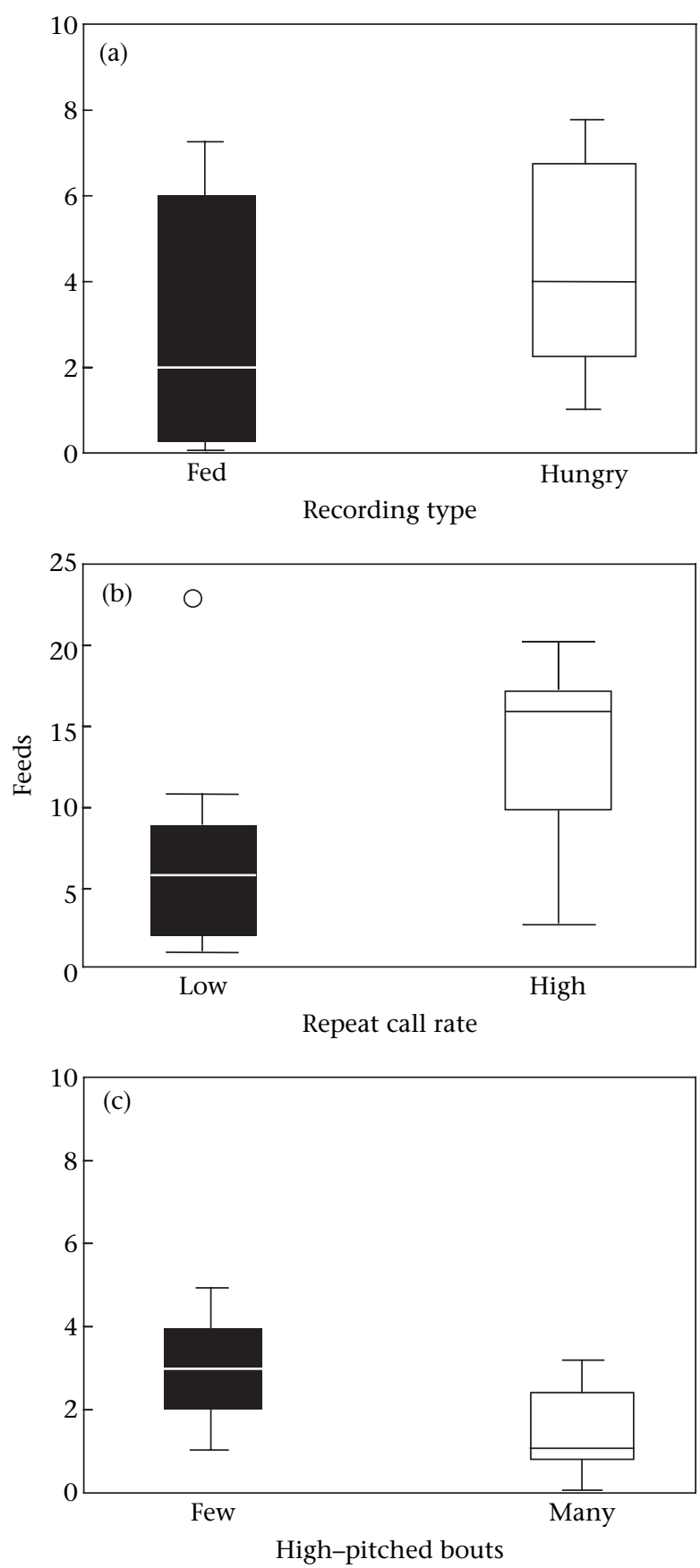

Figure 4. Number of feeds (calculated per $1 \mathrm{~h}$ playback) by adults of the whole group (median with interquartile range) to speakers playing begging calls of the same pup (a) when either naturally fed or deprived of food for $1 \mathrm{~h}(\mathrm{~N}=7$ groups), (b) with two different begging rate playback treatments (low or high; $N=7$ groups) and (c) with a constant repeat call rate but with either few $(8 / 1 \mathrm{~h}$ playback) or many (28/1 h playback) high-pitched bouts ( $N=7$ groups).

therefore have a direct advantage in competition with other pups calling further away, as shown in a previous study (Manser \& Avey 2000). In addition, the closest pup is able to monitor the behaviour of the feeder and react by giving high-pitched calls at the moment the feeder finds food, thus influencing its decision to feed to the pup's benefit (Kunc et al. 2007).
Adults also used particular vocal cues as signals of need when making feeding decisions. When we removed the effect of pup proximity, by playing back recordings of fed and hungry pups from loudspeakers, adults still preferentially fed loudspeakers broadcasting the calls of hungry rather than fed pups. Hungry pups gave repeat calls at a higher rate and also increased the rate at which they gave bouts of high-pitched calls. However, adult meerkats fed at higher rates only when exposed to playbacks of high rates of repeat calls, and not to playbacks of increased bouts of high-pitched calls. This indicates that the rate of repeat calls is used as a signal of need. The main effect of an increased rate of repeat calls appeared to be the increase in food allocation of the potential feeders. Thereby, adults respond to an increased call rate by changing their generosity rather than their foraging effort (English et al. 2008). Repeat calls appeared to be less important in direct competition with littermates. Playing repeat calls does not discourage pups from following the loudspeaker any more than playing back adult contact calls (Manser \& Avey 2000). Whether pups cooperate in begging and decrease their call rate when another pup is close by, as has been suggested for the banded mongoose, Mungos mungo (Bell 2007), has still to be tested. As in birds, the effect of hunger on begging vocalizations primarily affected call rate rather than call structure (Hofstetter \& Ritchison 1998; Krebs 2001; Träger et al. 2006; but see Sacchi et al. 2002). Although previous experiments showed that the amplitude of the repeat calls influences which pup is fed (Manser \& Avey 2000), it remains to be tested whether amplitude affects the foraging effort or decision of adults in allocating food to pups.

The high-pitched call did not appear to function as a signal of need, but instead had a direct impact on the decision of whether and whom to feed. Although hungry pups in our experiments were more likely to give more frequent bouts of high-pitched calls than fed pups, the playback experiments showed that, additionally, randomly played call bouts did not influence the feeding rate by adults. High-pitched calls appeared to be confined to the event of finding a prey item by an adult or being fed. This has also been suggested in a previous study where no correlation between the duration of the last feed and the likelihood of giving high-pitched calls under natural foraging activities was found (Manser \& Avey 2000). Since hungry pups stay closer to potential feeders, they are better able to observe them and may give highpitched calls more often when the adults find food but eat it themselves (personal observation). Therefore, pups deprived of food for $1 \mathrm{~h}$ may have had a higher motivation to be fed than pups naturally foraging, and may have responded faster when an adult was about to find food and gave high-pitched calls more frequently. Previous experiments have shown that high-pitched calls indicate to feeders whom to feed, suggesting they are important in competition with other littermates close by (Kunc et al. 2007). However, high-pitched calls given at the time the adult finds the prey item may not only be used in competition with littermates, but also influence the adult's decision to give the prey to the pup, rather than to eat it by itself. Owing to the faster rate, 
higher peak frequency and amplitude of high-pitched calls in comparison to the repeat calls (Kunc et al. 2007), pups make themselves more obvious in the most crucial moment of the adult deciding on the allocation of food. This hypothesis is also supported by the observation that this call type is still given in groups with a single pup, although much less frequently than in litters with several pups (Kalahari Meerkat Project, unpublished data).

If adults provide more food to pups begging at a high rate, why do satiated pups not continue to call at a high rate to gain yet more food? A high repeat call rate may be associated with increased costs of producing these calls (Kilner \& Johnstone 1997). The fact that meerkats use different call types with differential effects on the feeding behaviour of adults suggests that they are adapted to specific contexts (Kunc et al. 2007). For example, the call rate within high-pitched call bouts, which are given only over short periods and are mainly related to the feeding event, did not differ between fed and hungry pups, indicating that this may be the highest possible rate of production for pups. When pups beg, they move their whole thorax vigorously (personal observation) and calls may therefore be energetically costly to produce. In the same way, pups that engage in foraging for themselves do not give repeat calls, but instead give much briefer, quieter digging calls (Manser \& Avey 2000; Kunc et al. 2007). Such calls result in less feeding by adults than repeat calls (Kunc et al. 2007). Meerkat pups that spend increased time foraging appear to gain benefits later in life, possibly by learning effective foraging techniques (Thornton 2008). Thus, wellfed meerkat pups may be trading off the immediate benefit of increased food delivery that offers little marginal benefit to them for future benefits of increased foraging efficiency. For hungry pups, the marginal benefit of an immediate feed is large, so when set against the discounted possible future benefits of foraging efficiency, the optimal behaviour is to invest in current begging effort and give begging calls at a high rate.

In dispersed feeding systems, the equivalent begging to that seen in stationary systems, with parent birds briefly interacting with chicks at the nest, appears to be divided into two discrete periods with different call types. Birds arriving at the nest assess the begging intensity not only of chicks but also of the whole brood and consequently choose whom to feed and how often. In meerkats, close proximity to the feeder and the rate of the continuously given repeat calls over long periods provide an indication of the young's need, and adults respond adaptively to these signals by increasing their feeding rate accordingly. High-pitched calls, mainly confined to the feeding event, more immediately influence the decision to allocate food and whom to feed, but they are not used as a signal of need. This shows that hunger may lead to several changes in vocal behaviour, only some of which may be used by adults to assess need. Owing to the exclusivity of effective begging versus the ability to forage, the trade-off between short- and long-term benefits and short- and long-term costs of begging may ensure the honesty of the signal.

\section{Acknowledgments}

We thank the family of Hennie Kotze for allowing us to work on their land, Johan Du Toit, Elissa Cameron and Martin Haupt at the Mammal Research Institute, University of Pretoria, for logistical support. We are grateful to Neil Jordan and Tom Flower as field managers, and to all of the students and volunteers who contributed to habituation of the population, data collection and discussions. We are in particular grateful to Adam Seward, Alison Geraldt and Maeva Dewas for their help in experiments, Sarah Hodge for discussions, and Rebecca Kilner for input on the manuscript. This project was funded by a grant given to M.B.M. from the Swiss National Science Foundations, SNF-Förderprofessur $\mathrm{Nr}$ 631-066129 and a NERC grant to T.H.C.B.

\section{References}

Bell, M. B. V. 2007. Cooperative begging in banded mongoose pups. Current Biology, 17, 717-721.

Bell, M. B. V. 2008. Strategic adjustment of begging effort by banded mongoose pups. Proceedings of the Royal Society of London, Series B, 275, 1313-1319.

Brotherton, P. N. M., Clutton-Brock, T. H., O'Riain, M. J., Gaynor, D., Sharpe, L., Kansky, R. \& Mcllrath, G. M. 2001. Offspring food allocation by parents and helpers in a cooperative mammal. Behavioral Ecology, 12, 590-599.

Chappell, M. A. \& Bachman, G. C. 2002. Energetic costs of begging behaviour. In: The Evolution of Begging: Competition, Cooperation and Communication (Ed. by J. Wright \& M. L. Leonard), pp. 143-162. Dordrecht: Kluwer.

Clutton-Brock, T. H., Gaynor, D., Kansky, R., MacColl, A. D. C., Mcllrath, G., Chadwick, P., Brotherton, P. N. M., O'Riain, M. J., Manser, M. \& Skinner, J. D. 1998. Costs of cooperative behaviour in suricates (Suricata suricatta). Proceedings of the Royal Society of London, Series B, 265, 185-190.

Clutton-Brock, T. H., Brotherton, P. N. M., O'Riain, M. J., Griffin, A. S., Gaynor, D., Kansky, R., Sharpe, L. \& Mcllrath, G. M. 2001. Contributions to cooperative rearing in cooperative meerkats. Animal Behaviour, 61, 705-710.

Draganoiu, T. I., Nagle, L., Musseau, R. \& Kreutzer, M. 2006. In a songbird, the black redstart, parents use acoustic cues to discriminate between their different fledglings. Animal Behaviour, 71, 1039-1046.

English, S., Kunc, H. P., Madden, J. M. \& Clutton-Brock, T. H. 2008. Sex differences in responsiveness to begging in a cooperative mammal. Biology Letters, 4, 334-337.

Engquist, L. 2005. The mistreatment of covariate interaction terms in linear model analyses of behavioural and evolutionary ecology studies. Animal Behaviour, 70, 967-971.

Gilchrist, J. S. 2004. Pup escorting in the communal breeding banded mongoose: behavior, benefits, and maintenance. Behavioral Ecology, 15, 952-960.

Glassey, B. \& Forbes, S. 2002. Muting individual nestlings reduces parental foraging for the brood. Animal Behaviour, 63, 779-786.

Godfray, H. C. J. 1995. Signalling of need between parents and young: parent-offspring conflict and sibling rivalry. American Naturalist, 146, 1-24.

Hodge, S., Flower, T. \& Clutton-Brock, T. H. 2007. Offspring competition and helper associations in cooperative meerkats. Animal Behaviour, 74, 957-964.

Hofstetter, S. H. \& Ritchison, G. 1998. The begging behavior of nestling eastern screech-owls. Wilson Bulletin, 110, 86-92. 
Johnstone, R. A. 2004. Begging and sibling competition: how should offspring respond to their rivals? American Naturalist, 163, 388-406.

Kilner, R. M. \& Johnstone, R. A. 1997. Begging the question: are offspring solicitation behaviours signals of need? Trends in Ecology \& Evolution, 12, 11-15.

Kilner, R. M., Nobel, D. G. \& Davies, N. B. 1999. Signals of need in parent-offspring communication and their exploitation by the common cuckoo. Nature, 397, 667-672.

Kölliker, M., Richner, H., Werner, I. \& Heeb, P. 1998. Begging signals and biparental care: nestling choice between parental feeding locations. Animal Behaviour, 55, 215-222.

Krebs, E. A. 2001. Begging and food distribution in crimson rosella (Platycercus elegans) broods: why don't hungry chicks beg more? Behavioral Ecology and Sociobiology, 50, 20-30.

Kunc, H. P., Madden, J. R. \& Manser, M. B. 2007. Begging signals in a mobile feeding system: the evolution of different call types. American Naturalist, 170, 617-624.

Leech, S. M. \& Leonard, M. L. 1997. Begging and the risk of predation in nestling birds. Behavioral Ecology, 8, 644-646.

Leonard, M. L. \& Horn, A. G. 1996. Provisioning rules in tree swallows. Behavioral Ecology and Sociobiology, 38, 341-347.

Leonard, M. L., Horn, A. G. \& Eden, S. F. 1988. Parent-offspring aggression in moorhens. Behavioural Ecology and Sociobiology, 23, 265-270.

Lessells, C. M. \& Parker, G. A. 1999. Parent-offspring conflict: the full-sib-half-sib fallacy. Proceedings of the Royal Society of London, Series B, 266, 1637-1643.

McRae, S. B., Weatherhead, P. J. \& Montgomerie, R. 1993. American robin nestlings compete by jockeying for position. Behavioral Ecology and Sociobiology, 33, 101-106.

Manser, M. B. \& Avey, G. 2000. The effect of pup vocalizations on food allocation in a cooperative mammal, the meerkat (Suricata suricatta). Behavioral Ecology and Sociobiology, 48, 429-437.
Mock, D. W. \& Parker, G. A. 1997. Siblicide, family conflict and the evolutionary limits of selfishness. Animal Behaviour, 56, 1-10.

Ottosson, U., Backman, J. \& Smith, H. G. 1997. Begging affects parental effort in the pied flycatcher, Ficedula hypoleuca. Behavioral Ecology and Sociobiology, 41, 381-384.

R Development Core Team. 2005. R: A Language and Environment for Statistical Computing. Vienna: R Foundation for Statistical Computing.

Royle, N. J., Hartley, I. R. \& Parker, G. A. 2002. Begging for control: when are offspring solicitation behaviours honest? Trends in Ecology \& Evolution, 17, 434-440.

Sacchi, R., Saino, N. \& Galeotti, P. 2002. Features of begging calls reveal general condition and need of food of barn swallow (Hirundo rustica) nestlings. Behavioral Ecology, 13, 268-273.

Smith, T. E., Leonard, M. L. \& Smith, B. D. 2005. Provisioning rules and chick competition in asynchronously hatching common terns (Sterna hirundo). Behavioral Ecology and Sociobiology, 58, 456-465.

Thornton, A. 2008. Early body condition, time budgets and the acquisition of foraging skills in meerkats. Animal Behaviour, 75, 951-962.

Träger, I., Masello, J.-F., Mundry, R. \& Quillfeldt, P. 2006. Do acoustic parameters of begging calls of Cory's shearwaters Calonectris diomedea reflect chick body condition? Waterbirds, 29, $315-320$

Trivers, R. L. 1974. Parent-offspring conflict. American Zoologist, 14, 249-264.

Venables, W. N. \& Ripley, B. D. 2002. Modern Applied Statistics with S. 4th edn. New York: Springer.

Weary, D. M. \& Fraser, D. 1995. Calling by domestic piglets: reliable signals of need? Animal Behaviour, 50, 1047-1055.

Wright, J. \& Leonard, M. L. 2002. The Evolution of Begging: Competition, Cooperation and Communication. Dordrecht: Kluwer. 